\title{
PERANCANGAN SISTEM KEAMANAN RUMAH BERBASIS IoT DENGAN NodeMCU ESP8266 MENGGUNAKAN SENSOR PIR HC-SR501 DAN SENSOR SMOKE DETECTOR
}

\author{
${ }^{1}$ M Reza Hidayat, ${ }^{2}$ Christiono, ${ }^{3}$ Budi Septiana Sapudin \\ ${ }^{1}$ Teknik Elektro Universitas Jenderal Achmad Yani, \\ ${ }^{2}$ Teknik Elektro Sekolah Tinggi Teknik-PLN, \\ ${ }^{3}$ Teknik Elektro Universitas Jenderal Achmad Yani, \\ ${ }^{1}$ mreza@lecturer.unjani.ac.id, ${ }^{2}$ Christiono@sttpln.ac.id
}

\begin{abstract}
Along with the development of science and technology, problems often occur that threaten security at home. These problems originate from a level of security that does not meet security standards at home. Various problems that can threaten home security conditions are fire hazards that can be caused by neglect of home temperature regulation and electrochemical equipment that is uncontrolled by the homeowner or thief danger that can easily enter the house. The design of the home security system prototype is programmed and controlled by the NodeMCU ESP-8266 to transmit all data from sensor readings to the interface on the Cayenne dashboard. PIR sensor (HC-SR501) has a digital output, if the sensor detects a movement, the NodeMCU ESP-8266 will give a logical value of one. Gas sensor concentration (MQ-02) in testing has an average difference of $2.79 \mathrm{ppm}$ (part per million). The reading results of all sensors will be measured through the Internet of Things interface displayed on the Cayenne dashboard, the simulated gas concentration with gas matches with the difference results, test results and analysis results of $2.79 \mathrm{ppm}$ (part per million) and if the gas sensor (MQ -02) Exceeds the specified parameters, the buzzer will sound. PIR sensor testing (HC-SR501) will work optimally by human movement if at an angle of $45^{\circ}$ because the success rate is $100 \%$ in ten experiments and in the $90^{\circ}$ angle the success rate is $80 \%$.
\end{abstract}

Keywords : Cayenne, Internet of Things, Home Security, Smoke Sensor, PIR (Passive Infrared Receiver) Sensor

\begin{abstract}
ABSTRAK
Seiring dengan perkembangan ilmu dan teknologi, sering terjadi permasalahan yang mengancam keamanan pada rumah. Permasalahan tersebut berawal dari tingkat keamanan yang tidak memenuhi standar keamanan pada rumah. Berbagai masalah yang dapat mengancam kondisi keamanan rumah yaitu bahaya kebakaran yang bisa disebabkan oleh lalainya pengaturan suhu rumah dan peralatan elektroknik yang tidak terkendali oleh pemilik rumah atau bahaya maling yang dapat dengan mudah masuk ke dalam rumah. Perancangan prototipe sistem keamanan rumah ini diprogram dan dikontrol oleh NodeMCU ESP-8266 untuk mengirimkan seluruh data hasil pembacaan sensor ke antar muka pada dashboard Cayenne. Sensor PIR (HC-SR501) memiliki keluaran digital, jika sensor mendeteksi adanya pergerakan maka NodeMCU ESP-8266 akan memberikan nilai logik satu. Konsesntrasi sensor gas (MQ-02) dalam pengujian memiliki selisih rata-rata 2,79 ppm (part per million). Hasil pembacaan seluruh sensor akan diukur melalui antar muka Internet of Things yang ditampilkan pada dashboard Cayenne, konsentrasi gas yang disimulasikan dengan korek gas dengan hasil selisih, hasil pengujian dan hasil analisa sebesar 2,79 ppm (part per million) serta jika sensor gas (MQ-02) melebihi parameter yang sudah di tentukan maka buzzer akan bunyi. Pengujian sensor PIR (HC-SR501) akan bekerja maksimal oleh pergerakan manusia jika dalam sudut $45^{\circ}$ karena tingkat keberhasilanya sebesar $100 \%$ dalam sepuluh kali percobaan dan dalam sudut $90^{\circ}$ tingkat keberhasilanya adalah sebesar $80 \%$.
\end{abstract}

Kata kunci : Cayenne, Internet of Things, Keamanan Rumah, Sensor Gas, Sensor PIR (Passive Infrared Receiver) 


\section{PENDAHULUAN}

Seiring dengan perkembangan ilmu dan teknologi, sering terjadi permasalahan yang mengancam keamanan pada rumah. Permasalahan tersebut berawal dari tingkat keamanan yang tidak memenuhi standar keamanan pada rumah [1]. Sistem keamanan di Indonesia sebagian besar masih belum menggunakan sistem keamanan yang standar untuk keamanan pada rumah [2]. Berbagai macam bentuk dan model alat pengaman yang sangat pesat ini didorong karena tingginya angka kejahatan yang terjadi saat ini. Melihat sering terjadinya tindak kejahatan yang dilakukan oleh pencuri dengan sasaran rumah-rumah penduduk baik yang sedang ditinggal oleh pemiliknya maupun tidak, membuat orang resah apabila hendak meninggalkan rumahnya tanpa berpenghuni [3]. Untuk mengatasi masalah pencuri sistem pemantau ruang jarak jauh dengan sensor PIR (Passive Infrared Receiver) dan untuk mengatasi masalah kebakaran dengan sensor gas (MQ-02).

Oleh karena itu teknologi yang mampu memberikan informasi tentang keadaan rumah secara realtime sangatlah diperlukan, salah satu teknologi yang dapat mendukung pengiriman notifikasi secara langsung dan jarak jauh adalah Internet Of Things (IoT) [4]. Dengan teknologi ini dapat memanfaatkan jaringan internet untuk menghubungkan kondisi rumah dengan pemiliknya melalui sebuah aplikasi pada perangkat smartphone. menerapkan sistem IOT "Internet Of Things" di rumah atau perkantoran, perangkat-perangkat listrik akan dapat bekerja secara otomatis sesuai dengan kebutuhan pengguna.

Internet of Things (IoT) merupakan suatu teknologi dimana beberapa perangkat elektronik dapat terhubung dan berkomunikasi melalui internet yang membuat mereka dapat mengirim dan menerima data secara realtime [5]. Agar ketika terdapat suatu kejadian yang berhubungan dengan keamanan rumah, dapat diketahui dengan cepat oleh pemilik rumah. Pada tugas akhir akan dilakukan pembuatan prototype sistem keamanan menggunakan teknologi Internet Of Things (IoT) dengan NodeMCU ESP-8266 sebagai mikrokontroler dan sensor pir HC-SR501 sebagai pedeteksi manusia, sensor gas (MQ02) sebagai pendeteksi gas, asap, dll.

\section{METODOLOGI PENELITIAN}

\subsection{Internet of Things}

Internet of Things adalah konsep yang muncul dimana semua alat dan layanan terhubung satu dengan yang lain dengan mengumpulkan, bertukar dan memproses data untuk beradaptasi secara dinamis. Di dalam bahasan "Smart Home Environments" antara IoT dan alat ataupun layanan tradisional berintegrasi di dalam rumah untuk meningkatkan kualitas hidup. Ini memungkinkan peningkatan di berbagai bidang seperti penghematan energi, pengamatan kesehatan, dan yang lainnya.

\subsection{NodeMCU ESP-8266}

NodeMCU ESP8266 adalah chip terintegrasi yang dirancang untuk menghubungkan mikrokontroler dengan internet melalui Wi-Fi. Ia menawarkan solusi jaringan Wi-Fi yang lengkap dan mandiri, yang memungkinkan untuk menjadi host ataupun sebagai Wi-Fi client. ESP8266 memiliki kemampuan pengolahan dan penyimpanan on-board yang kuat, yang memungkinkannya untuk diintegrasikan dengan sensor dan aplikasi perangkat khusus lain melalui GPIOs dengan pengembangan yang mudah serta waktu loading yang minimal. Tingkat integrasinya yang tinggi memungkinkan untuk meminimalkan kebutuhan sirkuit eksternal, termasuk modul front-end, dirancang untuk mengisi daerah PCB yang minimal [8]. 


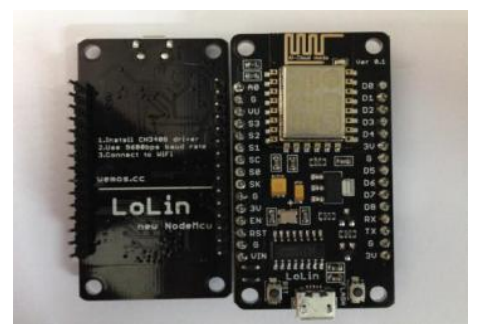

Gambar 1. NodeMCU ESP-8266

\subsection{Sensor PIR HC-SR501}

PIR (Passive Infrared Receiver) merupakan sebuah sensor berbasiskan infrared. Akan tetapi, tidak seperti sensor infrared kebanyakan yang terdiri dari LED dan fototransistor. PIR tidak memancarkan apapun seperti IR LED. Sesuai dengan namanya "Passive" sensor ini hanya merespon energi dari pancaran sinar inframerah pasif yang dimiliki oleh setiap benda yang terdeteksi olehnya. Benda yang bisa dideteksi oleh sensor ini biasanya adalah tubuh manusia.

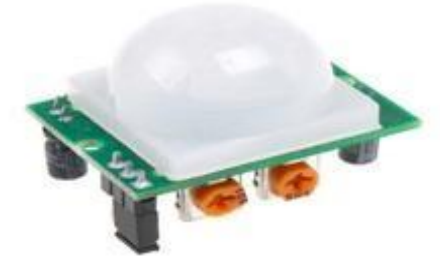

Gambar 2. Sensor PIR (HC-SR501)

Adapun persamaan untuk mencari nilai akurasi dari sensor PIR (HC-SR501), berikut adalah persamaan tersebut:

$$
\text { Nilai Akurasi }=\frac{n-x}{n} X 100 \%
$$

\subsection{Relay}

Relay adalah Saklar (Switch) yang dioperasikan secara listrik dan merupakan komponen Electromechanical (Elektromekanikal) yang terdiri dari 2 bagian utama yakni Elektromagnet (Coil) dan Mekanikal (seperangkat Kontak Saklar/Switch).

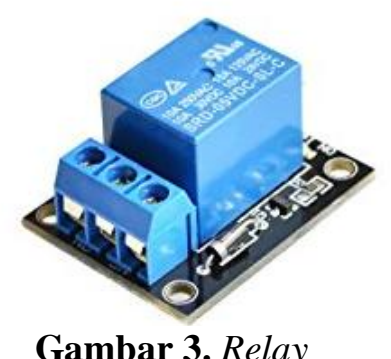

\subsection{Buzzer}

Buzzer Listrik adalah sebuah komponen elektronika yang dapat mengubah sinyal listrik menjadi getaran suara. Pada umumnya, Buzzer yang merupakan sebuah perangkat audio ini sering digunakan pada rangkaian anti-maling, Alarm pada Jam Tangan, Bel Rumah, peringatan mundur pada Truk dan perangkat peringatan bahaya lainnya. 


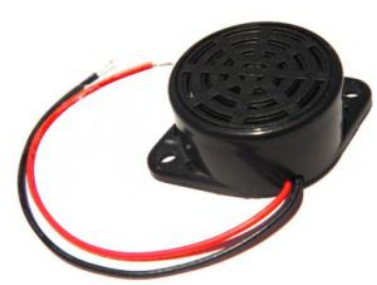

Gambar 4. Buzzer

\subsection{Sensor Smoke Detectors}

Smoke detectors adalah alat yang berfungsi sebagai pendeteksi adanya asap adapun sumber asap hasil dari pembakaran, prinsip kerjanya apabila asap mengenai sensor dalam waktu \pm 5 detik secara terus menerus maka sensor mengirim sinyal dalam bentuk suara. Dan membutuhkan tegangan +9 VDC sebagai catu daya [7].

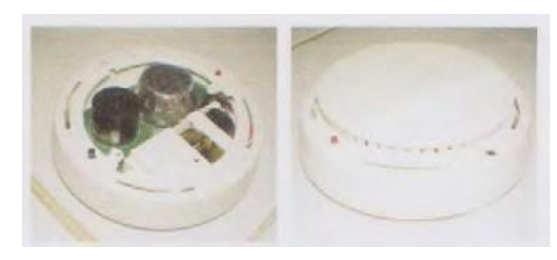

Gambar 5. Sensor Smoke Detectors

\subsection{Diagram Blok Perancangan Maket}

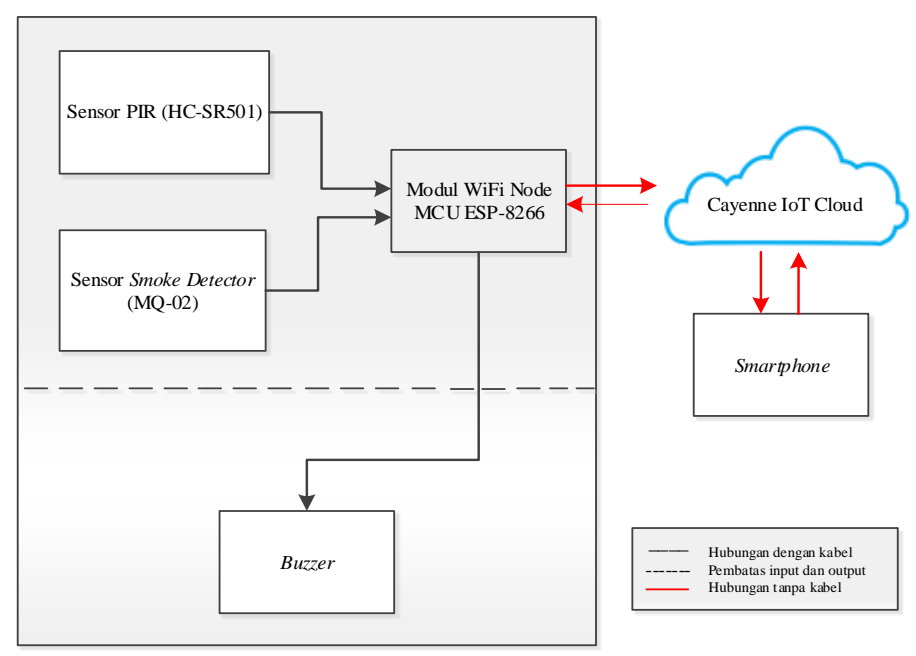

Gambar 6. Diagram Blok Perancangan Maket

\subsection{Perancangan alat mekanik (miniatur rumah)}

Perancangan alat mekanik (miniatur rumah) ini bertujuan untuk mengetahui penempatan dan pemasangan perangkat sensor PIR (HC-SR501), sensor gas (MQ-02), modul relay, perangkat NodeMCU ESP-8266, dan buzzer. Perancangan miniatur rumah ini dirancang dengan bentuk tiga dimensi dan terdapat 4 ruangan yaitu ruang tamu, dapur, kamar mandi, dan kamar tidur. Miniatur rumah ini di rancang dengan ukuran lebar $60 \mathrm{~cm}$ dan tinggi $40 \mathrm{~cm}$. 


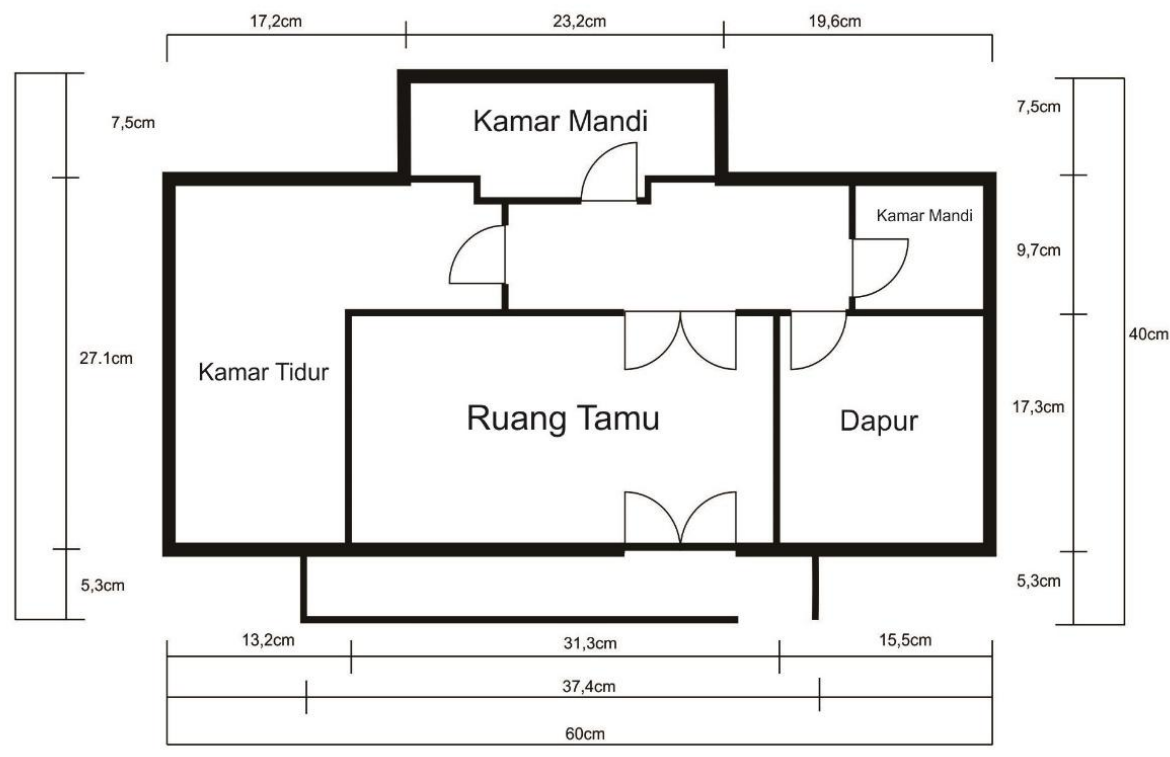

Gambar 7. Perancangan alat mekanik (miniatur rumah)

\section{HASIL DAN PEMBAHASAN}

\subsection{Realisasi Mekanik}

\subsubsection{Realisasi Mekanik Maket Rumah}

Mekanik yang direalisasikan berupa maket sebuah rumah dengan dimensi $65 \mathrm{~cm} \times 45 \mathrm{~cm} \times$ $10 \mathrm{~cm}$ dengan menggunakan bahan styrofoam setebal $1,3 \mathrm{~cm}$ untuk bangunan rumah dan kayu triplek untuk landasan rumah. Realisasi mekanik ditunjukan pada Gambar 8

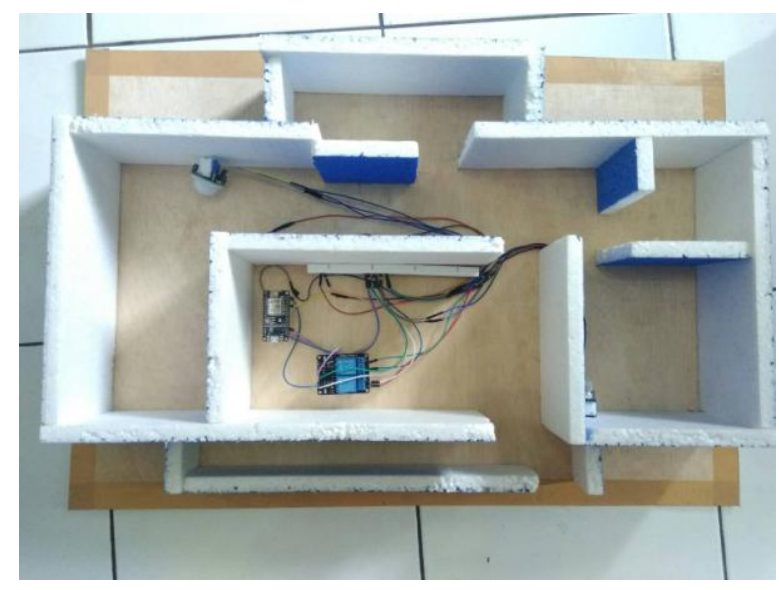

Gambar 8. Realisasi Mekanik Maket Rumah

\subsubsection{Realisasi mekanik untuk simulasi sensor PIR (HC-SR501) dan modul relay}

Mekanik untuk simulasi sensor PIR (HC-SR501) berupa sebuah ruangan dengan dimensi $27 \mathrm{~cm} \times 17 \mathrm{~cm} \times 10 \mathrm{~cm}$ dan penyimpanan sensor PIR (HC-SR501) serta buzzer dekat dengan pintu masuk dan menghadap ke kamar tidur agar sensor PIR (HC-SR501) dapat membaca jika terjadi suatu pergerakan di ruangan tersebut. Realisasi untuk sensor PIR (HC-SR501) dan buzzer ditunjukan pada Gambar 9. 


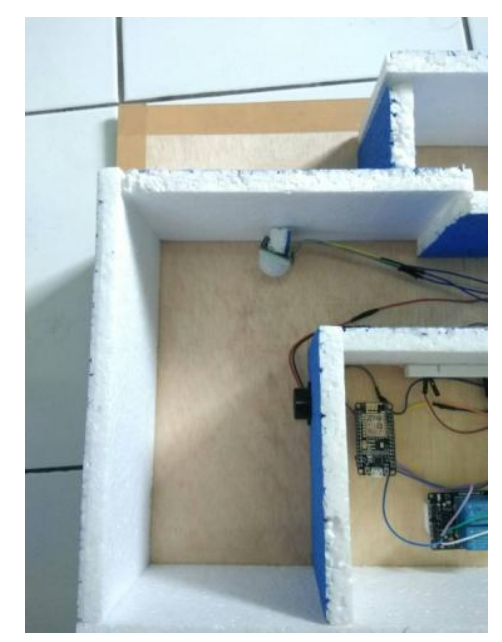

Gambar 9. Realisasi mekanik sensor PIR dan modul relay

\subsubsection{Realisasi mekanik untuk simulasi sensor MQ-02 dan modul relay}

Mekanik untuk simulasi sensor MQ-02 berupa sebuah ruangan dengan dimensi $17 \mathrm{~cm} \times 15 \mathrm{~cm}$ $\mathrm{x} 10 \mathrm{~cm}$. Ruangan ini dilengkapi dengan sensor gas dan buzzer. Ruangan ini di desain dengan dimensi kecil agar sensor gas dapat mendeteksi dengan cepat apabila terjadi gas bocor, asap, dll. Realisasi untuk sensor gas dan buzzer ditunjukan pada Gambar 10.

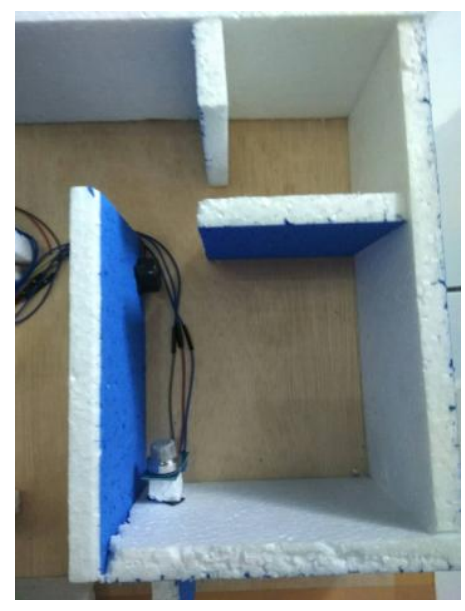

Gambar 10. Realisasi mekanik sensor gas dan modul relay

\subsection{Pengujian validasi persepsi objek dan jarak sensor PIR (HC-SR501)}

Pengujian validasi pada sensor PIR (HC-SR501) ini dilakukan untuk mengetahui objek, jarak dan sudut yang dapat dijangkau oleh sensor PIR (HC-SR501) ini pada saat seseorang atau pencuri memasuki rumah. Pengujian dilakukan dengan cara memberikan objek yang berupa manusia, hewan dan tumbuhan melewati sensor PIR (HC-SR501). Lalu pengujian terhadap jarak dan sudut dilakukan dengan cara memberikan objek dengan jarak dan sudut yang berbeda-beda, untuk jarak diberikan $1 \mathrm{~m}$ dan $5 \mathrm{~m}$ sedangkan untuk sudut yang diukur adalah $45^{\circ}$ dan $90^{\circ}$. Pengujian validasi objek dan jarak sensor PIR (HC-SR501) ditunjukan pada Tabel 1. 
Tabel 1. Pengujian validasi objek dan jarak sensor PIR

\begin{tabular}{|c|c|c|c|c|}
\hline \multirow{2}{*}{ Jarak (m) } & \multicolumn{2}{|c|}{$45^{\circ}$} & \multicolumn{2}{|c|}{$90^{\circ}$} \\
\hline & Manusia & Kucing & Manusia & Kucing \\
\hline \multirow{10}{*}{1} & $\mathrm{v}$ & $\mathrm{v}$ & $\mathrm{v}$ & $\mathrm{X}$ \\
\hline & $\mathrm{v}$ & $\mathrm{v}$ & $\mathrm{v}$ & $\mathrm{v}$ \\
\hline & $\mathrm{v}$ & $\mathrm{v}$ & $\mathrm{v}$ & $\mathrm{v}$ \\
\hline & $\mathrm{v}$ & $\mathrm{X}$ & $\mathrm{v}$ & $\mathrm{X}$ \\
\hline & $\mathrm{v}$ & $\mathrm{X}$ & $\mathrm{v}$ & $\mathrm{X}$ \\
\hline & $\mathrm{v}$ & $\mathrm{v}$ & $\mathrm{v}$ & $\mathrm{v}$ \\
\hline & $\mathrm{v}$ & $\mathrm{X}$ & $\mathrm{v}$ & $\mathrm{X}$ \\
\hline & $\mathrm{v}$ & $\mathrm{X}$ & $\mathrm{v}$ & $\mathrm{X}$ \\
\hline & $\mathrm{v}$ & $\mathrm{v}$ & $\mathrm{v}$ & $\mathrm{v}$ \\
\hline & $\mathrm{v}$ & $\mathrm{v}$ & $\mathrm{v}$ & $\mathrm{X}$ \\
\hline \multirow{10}{*}{5} & $\mathrm{v}$ & $\mathrm{X}$ & $\mathrm{X}$ & $\mathrm{X}$ \\
\hline & $\mathrm{v}$ & $\mathrm{X}$ & $\mathrm{v}$ & $\mathrm{X}$ \\
\hline & $\mathrm{X}$ & $\mathrm{v}$ & $\mathrm{v}$ & $\mathrm{X}$ \\
\hline & $\mathrm{v}$ & $\mathrm{X}$ & $\mathrm{v}$ & $\mathrm{X}$ \\
\hline & $\mathrm{v}$ & $\mathrm{X}$ & $\mathrm{v}$ & $\mathrm{X}$ \\
\hline & $\mathrm{v}$ & $\mathrm{v}$ & $\mathrm{v}$ & $\mathrm{X}$ \\
\hline & $\mathrm{v}$ & $\mathrm{X}$ & $\mathrm{v}$ & $\mathrm{X}$ \\
\hline & $\mathrm{X}$ & $\mathrm{v}$ & $\mathrm{v}$ & $\mathrm{X}$ \\
\hline & $\mathrm{v}$ & $\mathrm{X}$ & $\mathrm{v}$ & $\mathrm{X}$ \\
\hline & $\mathrm{v}$ & $\mathrm{X}$ & $\mathrm{v}$ & $\mathrm{X}$ \\
\hline
\end{tabular}

Berdasarkan data yang diperoleh pada Tabel 1 dapat diperoleh nilai akurasi dengan persamaan yang ditunjukan pada 2.1. Bahwa sensor PIR (HC-SR501) akan bekerja maksimal jika yang di deteksi oleh sensor adalah manusia karena tingkat keberhasilannya mencapai $100 \%$ dari 10 kali percobaan, sedangkan ketika pengujian sensor dilakukan terhadap hewan (kucing) tingkat keberhasilan hanya $60 \%$ yang dimana data ini tidak maksimal untuk dikirimkan ke basis data. Lalu dari data yang terakhir didapat sensor PIR (HC-SR501) tidak bisa mendeteksi keberadaan obyek tumbuhan dengan didapatnya data tingkat keberhasilan sebesar $0 \%$ dalam 10 kali percobaan ini. Lalu sudut pengambilan data hanya mempengaruhi kemampuan pembacaan sensor yang ingin di baca, sehingga dari data yang diperoleh dapat disimpulan bahwa sensor PIR (HC-SR501) ini berfungsi untuk mendeteksi gerakan manusia ketika ditempatkan di area penempatan yang tepat.

Untuk pembacaan sensor dengan jarak 5m tingkat keberhasilan pembacaan sensor PIR (HCSR501) untuk objek manusia adalah sebesar $80 \%$ yang dikarenakan $20 \%$ error disebabkan pembacaan yang tidak terbaca dengan baik karena jarak yang jauh sehingga sensor PIR (HCSR501) tidak bisa membaca objek yang ditentukan, sedangkan untuk kucing dan tumbuhan tingkat keberhasilan sensor PIR (HC-SR501) adalah 0\% yang dimana error pembacaan sensor yang terjadi adalah $100 \%$ yang disebabkan oleh pancaran energi panas yang dikeluarkan kucing tidak terdeteksi oleh sensor PIR (HC-SR501)

\subsection{Pengujian sensor (MQ-02)}

Sensor gas (MQ-02) ini mendeteksi konsentrasi gas yang mudah terbakar di udara serta asap, dan output membaca sebagai tegangan analog. Sensor gas (MQ-02) dapat diatur sensitifitasnya dengan memutar trimpot. Sensor gas ini biasa digunakan untuk mendeteksi kebocoran gas baik di rumah, kantor, perusahaan maupun di industri. 
Tabel 2. Pengukuran tegangan input sensor gas (MQ-02)

\begin{tabular}{|c|c|c|}
\hline Pengujian & $\begin{array}{c}\text { Tegangan NodeMCU ESP- } \\
\mathbf{8 2 6 6}\end{array}$ & $\begin{array}{c}\text { Hasil } \\
\text { Pegukuran }\end{array}$ \\
\hline 1 & 5 VDC & 4,09 VDC \\
\hline 2 & 5 VDC & 4,08 VDC \\
\hline 3 & 5 VDC & 4,09 VDC \\
\hline 4 & 5 VDC & 4,10 VDC \\
\hline 5 & 5 VDC & 4,10 VDC \\
\hline 6 & 5 VDC & 4,09 VDC \\
\hline 7 & 5 VDC & 4,07 VDC \\
\hline 8 & 5 VDC & 4,07 VDC \\
\hline 9 & 5 VDC & 4,08 VDC \\
\hline 10 & 5 VDC & 4,08 VDC \\
\hline
\end{tabular}

Hasil pengujian sensor gas (MQ-02) ini di ambil dalam bentuk data ppm (part poer million) melalui antar muka pada dashboard Cayenne. Pengujian konsentrasi gas ini dilakukan dengan mensimulasikan kebocokan gas dengan menggunakan korek api gas, ketika pemicu korek api gas ditekan maka sensor akan secara langsung membaca konsentrasi gas yang dilepaskan oleh korek api gas tersebut. Hasil pengujian ini akan dimuat dalam bentuk tabel pengujian dan grafik pengujian konsentrasi sensor gas (MQ-02). Berikut hasil pengujian tersebut:

Tabel 3. Hasil pengujian konsentrasi sensor gas (MQ-02)

\begin{tabular}{|c|c|c|c|}
\hline NO & $\begin{array}{c}\text { Konsentrasi } \\
\text { Gas Teruji } \\
\text { (ppm) }\end{array}$ & $\begin{array}{c}\text { Konsentrasi } \\
\text { Gas } \\
\text { Terhitung } \\
\text { (ppm) }\end{array}$ & $\begin{array}{c}\text { Tegangan } \\
\text { Keluaran } \\
\text { Terhitung }\end{array}$ \\
\hline 1 & 0 & 0 & 0 \\
\hline 2 & 214,0 & 215,67 & 2,37 \\
\hline 3 & 257,0 & 259,35 & 2,85 \\
\hline 4 & 316,0 & 319,41 & 3,51 \\
\hline 5 & 455,0 & 459,55 & 5,00 \\
\hline 6 & 431,0 & 434,98 & 4,78 \\
\hline 7 & 402,0 & 405,86 & 4,46 \\
\hline 8 & 389,0 & 392,82 & 4,32 \\
\hline 9 & 353,0 & 356,72 & 3,92 \\
\hline 10 & 321,0 & 323,96 & 3,56 \\
\hline 11 & 298,0 & 300,21 & 3,31 \\
\hline 12 & 288,0 & 290,2 & 3,20 \\
\hline 13 & 264,0 & 266,63 & 2,93 \\
\hline 14 & 260,0 & 262,08 & 2,88 \\
\hline 15 & 255,0 & 257,53 & 2,83 \\
\hline Rata-rata & 300,2 & 302,99 & \\
\hline (ppm) & 2,79 & & \\
\hline Selisih (ppm) & & & \\
\hline
\end{tabular}




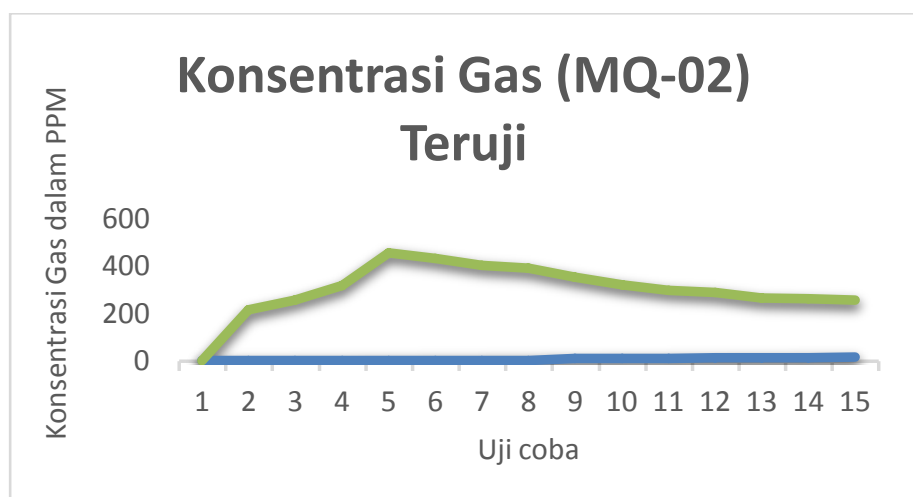

Gambar 11. Grafik konsentrasi gas (MQ-02) teruji

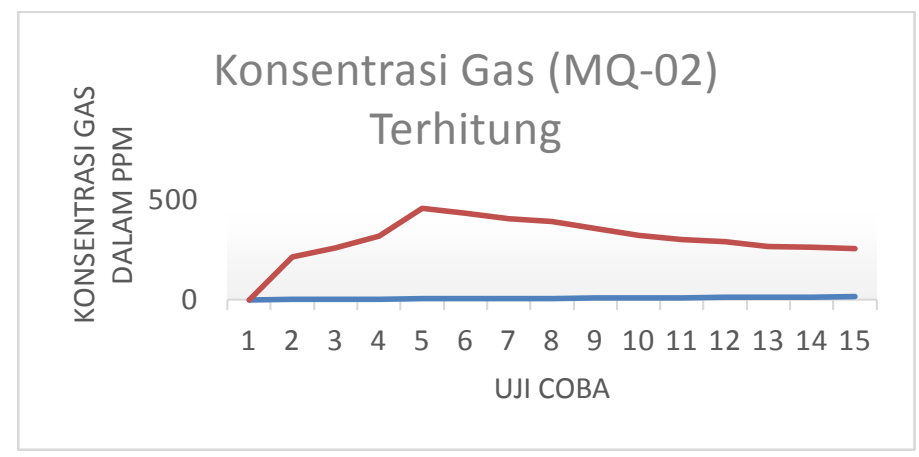

Gambar 12. Grafik konsentrasi gas (MQ-02) terhitung

Berdasarkan Tabel 3 diatas menunjukan bahwa pengujian konsentrasi gas menurut pengujian dan perhitungan konversi gas memiliki selisih rata-rata 2,79 ppm (part per million) dari pengujian konsentrasi gas tersebut. Berikut gambar yang menjelaskan hasil pembacaan konsentrasi gas berdasarkan hasil pengujian dan hasil perhitungan, Gambar 11 dan Gambar 12 diatas memiliki kesamaan bentuk karena berdasarkan Tabel 3 telah diketahui bahwa pembacaan konsentrasi gas tersebut memiliki selisih rata-rata sebesar 2,79 ppm (part per million), hal tersebut memastikan bahwa bentuk perubahan grafik pembacaan konsentrasi gas akan serupa dan sesuai dengan tabel hasil pengujian.

\section{KESIMPULAN}

Berdasarkan hasil perancangan pengujian dan analisis yang dilakukan penulis didapatkan hasil berupa kesimpulan. Pertama pemanfaatan konsep Internet of Things berfungsi untuk sistem keamanan rumah ketika kecepatan akses internet yang didapat oleh NodeMCU ESP-8266 cepat, hubungan data perubahan yang terjadi pada setiap perangkat akan di update secara realtime dalam dashboard Cayenne. Kedua sensor konsentrasi gas (MQ-02) diuji selama lima belas kali dengan menggunakan korek api gas, hasil rata-rata pengujian sensor gas (MQ-02) sebesar 300,2 ppm dengan rata-rata sebesar 302,99 ppm dan selisih sebesar 2,79 ppm. Ketiga sensor PIR (HC-SR501) diuji dengan makhluk hidup (Manusia, Hewan, dan Tumbuhan) dengan sudut yang berbeda yaitu $45^{\circ}$ dan $90^{\circ}$. Dari data pengujian yang diperoleh tingkat keberhasilan yang bekerja paling maksimal adalah manusia karena tingkat keberhasilanya mencapai $100 \%$ dari sepuluh kali percobaan, sedangkan kucing tingkat keberhasilanya sebesar $60 \%$ dan tumbuhan tingkat keberhasilanya sebesar $0 \%$. 


\section{DAFTAR PUSTAKA}

\section{Jurnal}

[1] A. G. d. Slamet, "Sistem pemantau ruang jarak jauh dengan sensor passive infrared berbasis mikrokontroler AT89S52," vol. 7, p. 2, 2013.

[2] E. A. d. Wildia, "Sistem ortomatis perekaman video dengan kamera CMOS 12 LED berbasis mikrokontroler AT89S51 menggunakan sensor PIR (Passive Infrared)," vol. 2, p. 1, 2013.

[3] J. Lestari, "Webcam monitoring ruangan menggunakan sensor gerak PIR (Passive Infrared)," vol. 2, p. 3, 2011.

[4] D. J. V. A. R. H. Suresh P, "A state of the art review on the Internet of Things (IoT) History," 2014.

[5] R. Permana, "Perancangan sistem keamanan dan kontrol smart home berbasis Internet Of Things," p. 1, 2017.

[6] M. N. R. A. F. Fredy Susanto, "Internet Of Things pada sistem keamanan ruangan, studi kasus ruang server perguruan tinggi raharja," p. 2, 2017.

[7] A. R. H. Abdul Ghofur, "Membangun pengontrol peralatan keamanan rumah dengan menggunakan AT89C51 dan borland delphi 6," 2016.

[8] A. Marvin, "Sistem keamanan ruman berbasis Internet Of Things (IoT) dengan Raspberry Pi," p. 2, 2017.

[9] Musthopa, "Sistem keamanan rumah berabasis RFID terintegrasi dengan sms gateway sebagai sistem peringatan dini kepada pemilik rumah," 2015. 